\title{
Valores Energéticos e Aminoácidos Digestíveis da Semente do Capim-Arroz (Echinochloa spp) para Aves
}

\section{Paulo Borges Rodrigues ${ }^{1}$, Wilson Moreira Dutra Júnior ${ }^{2}$, Horacio Santiago Rostagno ${ }^{3}$, Kênia Ferreira Rodrigues ${ }^{4}$}

\footnotetext{
RESUMO - Foram conduzidos três experimentos com o objetivo de avaliar o valor nutritivo da semente do capim-arroz (Echinochloa spp) para aves. No experimento I, foram utilizados 12 galos adultos, intactos, para determinação dos valores de energia metabolizável (EM) verdadeira corrigida pelo nitrogênio retido (EMVn), por intermédio do método da alimentação forçada, onde seis galos foram forçados a ingerir $30 \mathrm{~g}$ do alimento e seis galos mantidos em jejum, para determinação das perdas endógenas e metabólicas. No experimento II, utilizaram-se 12 galos cecectomizados para determinar os coeficientes de digestibilidade verdadeira dos aminoácidos do alimento em teste, empregando-se a mesma metodologia. Para determinar os valores de EM aparente corrigida pelo nitrogênio retido (EMAn), utilizouse, no experimento III, o método tradicional de coleta total de excretas, com 80 pintos de marca comercial, em crescimento. A semente do capim-arroz foi incluída em uma ração-referência, contendo $20 \%$ de proteína bruta e $3.000 \mathrm{kcal}$ de EM/kg, na proporção de $25 \%$. A ração-referência e a ração-teste foram fornecidas para quatro repetições de 10 aves cada. Os valores energéticos determinados foram $1.813 \mathrm{kcal}$ de EMAn e $1.976 \mathrm{kcal}$ de EMVn/kg de matéria natural. Os coeficientes de digestibilidade verdadeira dos aminoácidos essenciais foram, em média, 78,2\% e o dos aminoácidos não-essenciais, 78,3\%. A treonina e a lisina apresentaram menor digestibilidade (65,8 e 67,2\%, respectivamente) e a fenilalanina $(86,4 \%)$, seguida da metionina $(86,0 \%)$, os maiores coeficientes de digestibilidade, entre os essenciais Entre os não-essenciais, a tirosina $(90,5 \%)$ e a cistina $(56,3 \%)$ apresentaram o maior e o menor coeficiente de digestibilidade, respectivamente.
}

Palavras-chave: alimento não-convencional, digestibilidade, energia metabolizável, frangos de corte, galos adultos, galos cecectomizados

\section{Energy Values and Digestible Amino Acids of Barnyardgrass Seeds (Echinochloa spp) for Poultry}

ABSTRACT - Three assays were carried out to evaluate the nutritive value of the barnyardgrass seeds (Echnochloa spp.) for poultry. In the first assay, twelve adult cockerels were used to determine the true metabolizable energy value corrected by nitrogen retained (TMEn), using the forced fed method. In this assay six cockerels were forced fed $30 \mathrm{~g}$ of the feed and six cockerels were fastened to determinate metabolic and endogenous losses. In the second assay, twelve cecectomized cockerels were used to determine the true digestibility coefficients of the amino acids in the tested feed, using the same metodology. To determinate the apparent metabolizable energy corrected by nitrogen retained (AMEn) in the thirth assay, the total excreta collection method was used, with 80 growing chicks of commercial strain. The barnyardgrass seed was included in the proportion of 25 percent of the reference diet, which contained $20 \%$ $\mathrm{CP}$ and $3000 \mathrm{kcal}$ of the $\mathrm{ME} / \mathrm{kg}$. The reference and test diets were fed to four replicates of ten birds each. The energy values determined were $1813 \mathrm{Kcal}$ AMEn and $1976 \mathrm{kcal}$ of the TMEn/kg as fed. The true digestibility coefficients of the essential and non essential amino acids were, in average, $78.2 \%$ and $78.3 \%$, respectively. The threonine and the lysine shown lower digestibility $(65.8$ and $67.2 \%$, respectively) and the phenilalanine $(86.4 \%)$ follow by the methionine $(86.0 \%)$ presented higher values among essential amino acids. The tyrosine $(90.5 \%)$ and cystine $(56.3 \%)$ presented higher and lower digestibility coefficients, respectively, among the non essential amino acids.

Key Words: alternative feed, metabolizable energy, digestibility, cecectomized cockerels, broilers, adult cockerels

\footnotetext{
1 Professor do Departamento de Zootecnia/UFLA, DSc (pborges@ufla.br). Pesquisador Bolsista do CNPq

2 Professor do Departamento de Zootecnia/UFRPE, DSc (dutrajr@ufrpe.br).

${ }^{3}$ Professor do Departamento de Zootecnia/UFV, PhD (rostagno@mail.ufv.br). Pesquisador Bolsista do CNPq

${ }^{4}$ Professora da UFT - Doutoranda do DZO/UFLA (rodrigueskf@uol.com.br).
} 


\section{Introdução}

O mercado brasileiro de produção de rações destinadas à alimentação animal absorve mais de $60 \%$ da produção anual de milho e farelo de soja (ANFAL, 2003), sendo estes dois ingredientes considerados fundamentais nas formulações. $\mathrm{Na}$ formulação de uma dieta de custo mínimo, a composição dos ingredientes, a exigência animal e o custo são os três fatores avaliados. Estas condições, no entanto, complicam-se quando se pretende considerar a absorção do nutriente (Bellaver, 1994). $\mathrm{O}$ conhecimento dos valores energéticos e da digestibilidade dos aminoácidos, tanto do milho como de outros alimentos, é particularmente importante nestas formulações, uma vez que permite a utilização de ingredientes variados, como os subprodutos industriais e alimentos alternativos, dispensando a utilização de margem de segurança, que, muitas vezes, não é suficiente para garantir máximo desempenho (Albino e Silva, 1996).

O interesse pela digestibilidade ou disponibilidade dos aminoácidos cresceu nos últimos anos, e é bem conhecida a importância de se considerar a digestibilidade nas formulações. Sabe-se também que as quantidades de aminoácidos digestíveis, na maioria dos alimentos, são substancialmente menores que a total e, associado a isto, o desenvolvimento de ensaios de digestibilidade mais rápidos, bem como o aperfeiçoamento daqueles já existentes, tornou possível a condução de mais pesquisas relacionadas ao assunto (Parsons, 1996).

Por outro lado, em várias regiões do país há disponibilidade de alimentos não-convencionais, que podem se tornar alternativa viável nas formulações de rações para aves. Na região Sul do país, particularmente naquelas produtoras de arroz irrigado, a lavoura de arroz proporciona grande quantidade de subprodutos a partir de sua colheita e beneficiamento (Olivo et al., 1991). A semente do capim-arroz (Echinochloa spp.) é um subproduto que varia de 1 a $2 \%$ do total de arroz produzido (Dutra Jr. et al., 1994), com valor de proteína entre 7,42 e 12,11\% e de fibra bruta entre 11,29 e 27,36\%, dependendo da amostra coletada em diferentes lavouras da região de Uruguaiana, tornando-se uma alternativa nesta região. Martinez et al. (1983) e Du Bois et al. (1989) mostraram que é possível incluir até $25 \%$ deste alimento na ração de frangos de corte, em substituição ao milho, com melhora no ganho de peso e sem prejuízo na conversão alimentar. Dessa forma, o conhecimento do valor nutritivo deste alimento não-convencional, principalmente dos valores energéticos (energias metabolizável aparente - EMA e verdadeira - EMV) para aves, bem como dos coeficientes de digestibilidade verdadeira dos aminoácidos e, conseqüentemente, a composição em aminoácidos digestíveis verdadeiros, pode tornar-se de grande importância na formulação de rações, constituindo-se os objetivos do presente trabalho.

\section{Material e Métodos}

Três ensaios experimentais foram conduzidos para avaliar o valor nutritivo da semente de capim-arroz (Echinochloa spp), para aves. No primeiro experimento, utilizou-se o método da alimentação forçada descrito por Sibbald (1976), com modificações, para determinação da EMV corrigida pelo nitrogênio retido (EMVn), com galos Leghorn adultos de 18 meses de idade e peso médio de $2352 \pm 205 \mathrm{~g}$. O alimento a ser testado foi fornecido a seis galos e, simultaneamente ao período de coleta, seis galos foram mantidos em jejum para determinação das perdas endógenas e metabólicas. Após jejum de 24 horas, para esvaziar o trato digestivo, os galos foram forçados a ingerir $30 \mathrm{~g}$ da semente do capim-arroz, por meio de um funil-sonda introduzido via esôfago até o papo. Foram fornecidos $15 \mathrm{~g}$ do alimento às $8 \mathrm{~h}$ e $15 \mathrm{~g}$ às $16 \mathrm{~h}$, para evitar regurgitações. As bandejas sob o piso das gaiolas foram revestidas com plástico e a coleta de excretas realizada duas vezes ao dia ( 8 e $16 \mathrm{~h}$ ) para evitar fermentações, por um período de 56 horas, após o primeiro fornecimento do alimento.

As excretas foram coletadas e acondicionadas em freezer até o final do experimento, quando foram descongeladas, devidamente quantificadas, homogeneizadas e secas em estufa de ventilação forçada a $55^{\circ} \mathrm{C}$, por 72 horas. Posteriormente, as amostras do alimento e das excretas foram analisadas em matéria seca e nitrogênio, segundo as metodologias descritas por Silva (1990). Os valores energéticos foram calculados pelas fórmulas:

$$
\begin{gathered}
\text { EMA }(\mathrm{kcal} / \mathrm{kg} \text { de } \mathrm{MS})=\frac{\text { EB ingerida }- \text { EB excretada }}{\text { MS ingerida }} \\
\frac{\text { EB ingerida }-(\text { EB excretada }+8,22 * \mathrm{BN})}{\text { MS ingerida }}
\end{gathered}
$$

\section{R. Bras. Zootec., v.33, n.5, p.1192-1196, 2004}


$\operatorname{EMV}(\mathrm{kcal} / \mathrm{kg}$ de MS $)=$

EB ingerida - (EB excretada - EB do endógeno) MS ingerida

EMVn do alimento $=$

EB ingerida - (EB excretada - EB do endógeno + $8,22 * \mathrm{BNV})$

MS ingerida

em que $\mathrm{EB}$ = energia bruta; $\mathrm{MS}$ = matéria seca; EMAn $=$ EMA corrigida pelo nitrogênio retido; $\mathrm{BN}=$ balanço de nitrogênio; EMVn = EMV corrigida pelo nitrogênio retido e $\mathrm{BNV}=\mathrm{BN}$ verdadeiro.

No segundo experimento, seguiu-se a mesma metodologia, utilizando-se a adaptação do método de alimentação forçada (Sibbald, 1979) com galos Leghorn adultos cecectomizados, de 21 meses de idade e peso médio de $2132 \pm 257 \mathrm{~g}$, para determinação dos coeficientes de digestibilidade verdadeira dos aminoácidos e do conteúdo de aminoácidos digestíveis verdadeiros da semente do capim-arroz. Os galos foram cecectomizados por laparotomia abdominal e anestesia local, conforme a metodologia descrita por Pupa et al. (1998). Adotou-se o mesmo procedimento experimental descrito para o primeiro experimento; as análises do conteúdo de aminoácidos foram realizadas no Laboratório da Eurolysine (Amiens - França).

Uma vez conhecida a quantidade de aminoácidos ingeridos e excretados, bem como a fração endógena determinada com os galos em jejum, determinaram-se os coeficientes de digestibilidade verdadeira de cada aminoácido (CDVaa), por intermédio da fórmula proposta por Rostagno \& Featherston (1977):

\section{CDVaa = aminoácido ingerido - aminoácido}

excretado + aminoácido da fração endógena aminoácido ingerido (em gramas)

Posteriormente, foi calculado o conteúdo de aminoácidos digestíveis verdadeiros do alimento testado.

No experimento III, foram utilizados 80 pintos de linhagem comercial, criados em galpão de alvenaria até a idade de 15 dias. Após, as aves foram transferidas para baterias metálicas e distribuídas aleatoriamente nas gaiolas das baterias, onde receberam a ração-teste (substituição do capim-arroz pela ração-referência em $25 \%)$ e a ração-referência (20\% de proteína bruta e $3000 \mathrm{kcal}$ de EM/kg), em quatro repetições de 10 aves cada (cinco machos e cinco fêmeas). As aves receberam as rações por nove dias - cinco de adaptação e quatro de coleta total de excretas (22 a 25 dias de idade). Após preparar devidamente as amostras e realizar as análises de MS, EB e nitrogênio, determinaram-se os valores de EMAn, de acordo com a fórmula apresentada por Matterson et al. (1965):

$$
\begin{aligned}
& \text { EMAn Alimento }=\text { EMAn Ração-referência }+(\text { EMAn } \\
& \text { Ração-teste }- \text { EMAn Ração-referência }) \\
& \text { grama/grama de substituição }
\end{aligned}
$$

\section{Resultados e Discussão}

A composição da semente do capim-arroz utilizada no presente trabalho assemelha-se à obtida por Dutra Jr. et al. (1994), com exceção do extrato etéreo, que, no presente trabalho, foi $38,4 \%$ inferior e do fósforo total, o qual foi, aproximadamente, três vezes superior ao valor médio apresentado pelos referidos autores (Tabela 1), quando comparados com base na matéria seca.

Na Tabela 2, são apresentados a composição em aminoácidos totais, os respectivos coeficientes de digestibilidade verdadeira, a partir dos quais se calculou a composição da semente do capim-arroz em aminoácidos digestíveis verdadeiros, e os valores energéticos determinados nos ensaios com frangos de corte (EMAN) e galos adultos (EMVn).

A composição do alimento em aminoácidos digestíveis é de fundamental importância, pois, segundo Rostagno et al. (1999), éimprescindível o uso adequado da composição em aminoácidos digestíveis verdadeiros na formulação, principalmente quando se utilizam alimentos não-convencionais. Observa-se que os coeficientes de digestibilidade dos aminoácidos essenciais foram, em média, 78,2\%, com valores de digestibilidade mais baixos para a treonina e lisina (65,8 e $67,2 \%$, respectivamente). O coeficiente médio de digestibilidade dos aminoácidos não-essenciais foi semelhante aos essenciais $(78,3 \%)$, observando-se o valor mais baixo para a cistina $(56,3 \%)$ e o mais alto para a tirosina $(90,5 \%)$.

Os valores energéticos determinados no presente trabalho para a semente do capim-arroz foram $1.813 \mathrm{kcal}$ de EMAn e $1.976 \mathrm{kcal}$ de EMVn/kg de matéria natural (Tabela 2). Como apresentou elevado teor de fibra e, possivelmente há também a presença de carboidratos não solúveis, certamente esta composição contribuiu para os baixos valores 
energéticos deste alimento. No entanto, nota-se que este valor energético se assemelha àqueles do farelo de arroz desengordurado e farelo de trigo (1808 e $1888 \mathrm{kcal}$ de EMAn/kg de matéria natural, respectivamente), apresentados nas Tabelas Brasileiras (Rostagno et al., 2000).

Vale ressaltar que o conhecimento do valor nutricional deste alimento não-convencional, mas de quantidade expressiva no Sul do país, particularmente nas regiões produtoras de arroz irrigado, torna-o uma fonte alternativa na formulação de rações para aves. Dutra Jr. et al (2000) observaram que a substituição do milho a $20 \%$ por resíduos da pré-limpeza do arroz é viável, com adição de enzimas. Sugere-se, entretanto, a condução de outros ensaios de desempenho e econômico, que possibilitem viabilizar seu uso em níveis adequados para bom desempenho das aves.

Tabela 1 - Composição bromatológica, teores de amido, metionina + cistina e lisina da semente do capim-arroz - SCA

Table 1 - Bromatological composition, starch, methionine plus cystine and lysine of the barnyardgrass seeds - SCA

\begin{tabular}{|c|c|c|}
\hline $\begin{array}{l}\text { Composição } \\
\text { Composition }\end{array}$ & $\mathrm{SCA}^{1}$ & $\mathrm{SCA}^{2}$ \\
\hline $\begin{array}{l}\text { Matéria seca (\%) } \\
\text { Dry matter }\end{array}$ & 90,69 & 88,74 \\
\hline Proteína bruta (\%) & 9,17 & 9,38 \\
\hline $\begin{array}{l}\text { Crude Protein } \\
\text { Energia bruta }(\mathrm{kcal} / \mathrm{kg}) \\
\text { Gross energy }\end{array}$ & 3.696 & - \\
\hline $\begin{array}{l}\text { Fibra bruta }(\%) \\
\text { Crude fibre }\end{array}$ & 15,51 & 15,30 \\
\hline $\begin{array}{l}\text { Extrato etéreo }(\%) \\
\text { Ether extract }\end{array}$ & 2,82 & 3,82 \\
\hline $\begin{array}{l}\text { Matéria mineral (\%) } \\
\text { Ash }\end{array}$ & - & 8,44 \\
\hline $\begin{array}{l}\text { Cálcio }(\%) \\
\text { Calcium }\end{array}$ & 0,14 & 0,09 \\
\hline $\begin{array}{l}\text { Fósforo total (\%) } \\
\text { Total phosphorus }\end{array}$ & 0,30 & 0,11 \\
\hline Amido $(\%)$ & 46,20 & - \\
\hline $\begin{array}{l}\text { Starch } \\
\text { Metionina + cistina }\end{array}$ & $0,36^{3}$ & - \\
\hline $\begin{array}{l}\text { Methionine plus cystine } \\
\text { Lisina } \\
\text { Lysine }\end{array}$ & $0,22^{3}$ & - \\
\hline
\end{tabular}

${ }^{1}$ Análises realizadas no Laboratório de Nutrição Animal do DZO/ UFLA.

2 Dados apresentados por Dutra Jr. et al. (1994).

${ }^{3}$ Análises realizadas no Laboratório da Eurolysine (Amiens França).

${ }^{1}$ Analyses were performed at the Animal Nutrition Laboratory of DZO/UFLA.

2 Data from Dutra Jr. et al. (1994).

${ }^{3}$ Analyses were performed at the Eurolysine Laboratory (Amiens-France).
Tabela 2 - Composição em aminoácidos totais, coeficientes de digestibilidade verdadeira dos aminoácidos (CDVaa) e seus respectivos desvios-padrão (DP), conteúdo em aminoácidos digestíveis verdadeiros (AADV) e valores energéticos (EMAn e EMVn) da semente do capim-arroz, para aves

Table 2 - Total amino acids composition, true digestibility coefficients of the amino acids (TDCaa) and yours respectives standard errors (SE), true digestible amino acids content (TDaa) and energy values (AMEn and TMEn) of the barnyardgrass seeds, for poultry

$\begin{array}{ccc}\text { Totais } & \text { CDVaa } & \text { AADV } \\ (\%)^{1} & (\%) & (\%)^{2} \\ \text { Total } & \text { TDCaa } & \text { TDaa } \\ (\%)^{1} & & \end{array}$

Aminoácidos essenciais

Essential amino acids

Metionina

$0,22 \quad 86,0(0,7) \quad 0,19$

Methionine

Lisina

Lysine

Treonina

Threonine

Arginina

Argynine

Histidina

Hystydine

Leucina

Leucyne

Isoleucina

Isoleucyne

Fenilalanina

Phenylalanine

Valina

Valyne

Média dos essenciais

Essential average

Metionina + cistina

Methionine plus cystine

Aminoácidos não-essenciais

Non essential amino acids

Cistina

Cystine

Alanina

Alanine

Serina

Seryne

Ácido glutâmico

$0,22 \quad 67,2(3,8) \quad 0,15$

Glutamic acid

Ácido aspártico

$0,34 \quad 65,8(0,5)$

0,22

Aspatic acid

Tirosina

$0,36 \quad 83,2(4,0)$

0,30

$0,20 \quad 80,9(2,2)$

0,16

$0,85 \quad 85,1(3,0)$

0,72

$0,39 \quad 81,6(2,5)$

0,32

$0,51 \quad 86,4(1,5)$

0,44

$0,48 \quad 72,5(6,1)$

0,35

- $\quad 78,2(0,8)$

$0,36 \quad 76,2(0,7)$

0,27

Tyrosine

Média dos não-essenciais

Non essential average

\begin{tabular}{ll}
\hline EMAn $(\mathrm{kcal} / \mathrm{kg})^{3}$ & 1813 \\
AMEn & \\
EMVn $(\mathrm{kcal} / \mathrm{kg})^{4}$ & 1976
\end{tabular}

TMEn

${ }^{1}$ Análises realizadas no Laboratório da Eurolysine (Amiens França).

${ }^{2}$ Calculados por meio dos coeficientes de digestibilidade verdadeira dos aminoácidos.

${ }^{3}$ Determinada com pintos em crescimento; ${ }^{4}$ Determinada com galos adultos.

${ }_{1}$ Analyses were performed at the Eurolysine Laboratory (Amiens - France).

${ }^{2}$ Calculated from the true digestibility amino acids coefficients.

${ }^{3}$ Determined with growing chicks; ${ }^{4}$ Determined with adult cockerels.

\section{R. Bras. Zootec., v.33, n.5, p.1192-1196, 2004}




\section{Conclusões}

Os valores energéticos da semente do capimarroz foram $1.813 \mathrm{kcal}$ de EMAn e $1.976 \mathrm{kcal} \mathrm{de}$ $\mathrm{EMVn} / \mathrm{kg}$ de matéria natural. O coeficiente de digestibilidade médio dos aminoácidos essenciais e não-essenciais foi de 78,3 e 78,2\%, respectivamente. Os coeficientes de digestibilidade da metionina mais cistina e da lisina foram 76,2 e $67,2 \%$, respectivamente.

\section{Literatura Citada}

ALBINO, L.F.T.; SILVA, M.A. Tópicos avançados em exigências nutricionais para frangos de corte. In: CONGRESSO INTERNACIONAL, 1; CONGRESSO NACIONAL, 6.; CONGRESSO ESTADUAL, 14., 1996, Porto Alegre. Anais... Porto Alegre: PUCRS - Faculdade de Zootecnia, Veterinária e Agronomia, 1996. p.59-64.

ANFAL - ASSOCIAÇÃO NACIONAL DOS FABRICANTES DE ALIMENTOS PARA ANIMAIS. 2003 Anfal e Sindirações. www.sindirações.com.br. (Acessado em 21/07/2003).

BELLAVER, C. Metodologias para determinação do valor das proteínas e utilização de valores disponíveis nas dietas de não ruminantes. In: SIMPÓSIO INTERNACIONAL DE NÃORUMINANTES - REUNIÃO ANUAL DA SOCIEDADE BRASILEIRA DE ZOOTECNIA, 31., 1994, Maringá. Anais... Maringá: Sociedade Brasileira de Zootecnia, 1994. p.1-23.

DUBOIS, A.M.; GUELLER, D.M.M.; RANGEL, E.V. et al. Uso do Capim arroz como substituto do milho em rações para Frangos de Corte. In: REUNIÃO ANUAL DA SOCIEDADE BRASILEIRA DE ZOOTECNIA, 26., 1989, Porto Alegre. Anais... Porto Alegre: Sociedade Brasileira de Zootecnia, 1989. p. 210.

DUTRA JR., W.M.; BRACINI NETO, J.; MOREIRA, J.C.S. et al. Substituição parcial do milho por resíduo da pré-limpeza do arroz com a adição de enzimas para frangos de corte. I. Desempenho produtivo. Revista da Faculdade de Zootecnia, Veterinária e Agronomia, v.7, n.1, p.105-108, 2000.

DUTRA JR., W.M.; SANDI, D.; TAROUCO, J.U. et al. Utilização da semente do capim-arroz (Echinichloa spp) triturada na alimentação de suínos na fase de terminação. Revista da Faculdade de Zootecnia, Veterinária e Agronomia, v.1, n.1, p.39-42, 1994.
MARTINEZ, O.L.; BONNECARRÊRE, L.M.; MARTINEZ; S.G.; et al. Efeito da substituição do milho por resíduos de limpeza do arroz em rações para frangos de corte na fase final. In: REUNIÃO ANUAL DA SOCIEDADE BRASILEIRA DE ZOOTECNIA, 20., 1983, Pelotas. Anais... Pelotas: Sociedade Brasileira de Zootecnia, 1983. p.7.

MATTERSON, L.D.; POTTER, L.M.; STUTZ, M.W. et al. The metabolizable energy of feed ingredients for chickens. Storss, Connecticut, The University of Connecticut, Agricultural Experiment Station, 1965. 11p. (Research Report, 7).

OLIVO, C.J.; BRUM, A.E.S.; RITTER, H. et al. Componentes e composição química do resíduo de limpeza do arroz e sua utilização na alimentação de novilhas leiteiras. Ciência Rural, v.21, n.2, p.257-266, 1991.

PARSONS, C.M. Digestible amino acids for poultry and swine. Animal Feed Science and Technology, v.59, n.1-3, p.147-153, 1996.

PUPA, J.M.R.; LEÃO, M.I.; CARVALHO, A.U. et al. Cecectomia em galos sob anestesia local e incisão abdominal. Arquivos Brasileiros de Medicina Veteinária e Zootecnia, v.50, n.5, p.531-535, 1998.

ROSTAGNO, H.S.; ALBINO, L.F.T.; DONZELE, J.L. et al. Tabelas brasileiras para aves e suínos - composição de alimentos e exigências nutricionais. Viçosa, MG: Universidade Federal de Viçosa, 2000. 141p.

ROSTAGNO, H.S.; FEATHERSTON, W.R. Estudos de métodos para determinar disponibilidade de aminoácidos em pintos. Revista da Sociedade Brasileira de Zootecnia, v.6, n.1, p.64-76, 1977.

ROSTAGNO, H.S.; NASCIMENTO, A.H.; ALBINO, L.F.T. Aminoácidos totais e digestíveis para aves. In: SIMPÓSIO INTERNACIONAL SOBRE NUTRIÇÃO DE AVES, 1999, Campinas. Anais... Campinas: FACTA, 1999. p.65-83.

SIBBALD, I.R. A bioassay for available amino acids and true metabolizable energy in feedstuffs. Poultry Science, v.58, n.3, p.668-673, 1979.

SIBBALD, I.R. A bioassay for true metabolizable energy in feedingstuffs. Poultry Science, v.55, n.1, p.303-308, 1976.

SILVA, D.J. Análise de alimentos (métodos químicos e biológicos). 2.ed. Viçosa, MG: Universidade Federal de Viçosa, 1990, 165p.

Recebido em: 11/08/03

Aceito em: 19/02/04 